\title{
Solid-state NMR spectroscopy for characterization of RNA and RNP complexes
}

\author{
Arun Kumar Sreemantula and $\odot$ Alexander Marchanka \\ Centre for Biomolecular Drug Research and Institute of Organic Chemistry, Leibniz University Hannover, Schneiderberg 38, 30167 Hannover, Germany \\ Correspondence: Alexander Marchanka (alexander.marchanka@oci.uni-hannover.de)
}

Received: 8 April 2020

Revised: 24 May 2020

Accepted: 27 May 2020

Version of Record published: 23 June 2020
Ribonucleic acids are driving a multitude of biological processes where they act alone or in complex with proteins (ribonucleoproteins, RNP). To understand these processes both structural and mechanistic information about RNA is necessary. Due to their conformational plasticity RNA pose a challenge for mainstream structural biology methods. Solidstate NMR (ssNMR) spectroscopy is an emerging technique that can be applied to biomolecular complexes of any size in close-to-native conditions. This review outlines recent methodological developments in ssNMR for structural characterization of RNA and protein-RNA complexes and provides relevant examples.

\section{Introduction}

Numerous cellular activities are carried out by RNA and RNP complexes. They carry genetic information, modulate gene expression, act like enzymes, guide the assembly of complex molecular machines [1]. The activity of RNA and RNPs depends on their well-defined three-dimensional (3D) architecture as well as active conformational dynamics. X-ray crystallography, nuclear magnetic resonance (NMR) and electron microscopy (EM) are the most important methods for structural studies of biomolecules. Both naked RNA and RNPs are challenging molecules for structural studies. RNA often does not crystallize and in such cases is non-eligible for X-ray crystallography, RNA also represents a difficult object for EM due to large conformational flexibility. Solution-state NMR, on the other hand, can deal with flexible molecules in solution, however, encounters severe limitations when applied towards high molecular mass molecules.

Solid-state NMR (ssNMR) is an emerging structural biology technique that does not have intrinsic molecular mass limitation, can be readily applied to non-crystalline samples and can provide structural information on the atomic scale. ssNMR has been showing tremendous progress in understanding the structure and dynamics of amyloid fibrills, membrane proteins and protein assemblies [2-5]. On the opposite, the application of ssNMR to RNA and RNPs has only emerged recently due to many challenges. Intrinsically lower spectral resolution in ssNMR is exacerbated by the low chemical shift dispersion of only four chemically similar ribonucleotides [6,7]. Furthermore, lower proton density in RNA makes it difficult to correlate different nucleotides with each other and obtain longrange distance restraints. Nevertheless, in the last decade significant progress has been achieved in the structural biology of RNA by ssNMR; in this review, we will briefly summarize the most important recent advances in sample preparation, resonance assignment and structural characterization of RNA and protein-RNA complexes by ssNMR.

\section{RNA preparation for ssNMR studies}

The main methods of RNA production for NMR studies are solid-phase synthesis and in vitro transcription. For better overview of different procedures of RNA synthesis and isotope labeling for ssNMR please refer to our recent review on this topic [8]. Briefly, for ssNMR studies of RNA typically nucleotide-type selective of even nucleotide-specific labeling of RNA is necessary. Solid-phase synthesis can provide with RNAs up to $70 \mathrm{nt}$ in length using commercially available phosphoramidites 
without any restriction in sequence [9] and nucleotide-specificity [10,11]. Moreover, atom-specific isotope labeling is possible, which however requires sophisticated organochemical synthesis of corresponding phosphoramidites [12]. Unfortunately, this approach is not accessible to most of the laboratories. On the other hand, an in vitro transcription method is easy to implement and can be employed to synthesize RNA longer than $10 \mathrm{nt}$ with sufficient yield and purity $[13,14]$. In vitro transcription can be performed as one pot reaction (Figure 1A), and uniform or nucleotide-type selective labeling of the RNA can be obtained using ${ }^{2} \mathrm{H} /{ }^{13} \mathrm{C} /{ }^{15} \mathrm{~N}$ isotope-labeled rNTPs $[8,15]$. To remove possible $5^{\prime}$ and $3^{\prime}$ inhomogeneities one can synthesize longer RNA and then cut them at desired positions using different ribozymes [8]. Segmental labeling is necessary for large RNAs (>40 nt), please see our recent review and comprehensive survey by Duss et al. [16] for details. After RNA synthesis and RNA purification (via PAGE or HPLC) and (optional) assembly of RNP complex, the sample must be prepared to be packed into ssNMR rotor (Figure 1A). To date, there are three major procedures of RNA or protein-RNA sample preparation for ssNMR studies.

In early days of ssNMR studies on nucleic acids samples were lyophilized, which ultimately led to broad resonances $[17,18]$ due to insufficient hydration of RNA. However, since the molecules were typically sitespecific labeled at one or two specific positions, structural information was extracted without any difficulties $[18,19]$. In the following studies, the lyophilized samples were gradually rehydrated in a controlled way to regain optimal resolution [20-22].

The second approach of sample preparation is freezing or flash-freezing of sample together with a cryoprotectant at low temperatures $(100-150 \mathrm{~K})$. This approach is widely used in the sample preparation for dynamic nuclear polarization (DNP) studies. Freezing of samples ultimately leads to large inhomogeneous line broadening due to freezing out of molecular motions [23]; the impact of such line broadening could be alleviated by specific labeling, specific magnetization transfer and multidimensional experiments. Corzilius group has shown the applicability of this approach towards RNA and is actively working in this area [24-26].

Finally, the most established method to date is the micro(nano) crystallization of RNA. This approach has been widely used for structural studies of proteins by ssNMR $[2,3,27]$ and since then has been also implemented for structural studies of RNA and RNPs with minor modifications [28,29]. The approach involves fast micro-crystallization or precipitation of RNA or protein-RNA solutions by different crystallization agents (typically including polyethylene glycol (PEG) and salts) using vacuum concentrators. Micro-crystallized samples are usually stable at broad range of temperatures and give reproducible high-resolution spectra.

Very recently Wang group has proposed a novel ethanol precipitation method, where ethanol is added to the RNA solution to instantly precipitate RNAs [30]. This approach may provide hydrated RNA; moreover, it was shown that Watson-Crick (WC) base pairs are preserved during this treatment. However, it remains to be seen if this method preserves RNA fold and if it keeps tertiary structural elements like loops, kink-turns or bulges intact [30]. Another method of sample preparation is the sedimentation of dissolved macromolecules from the
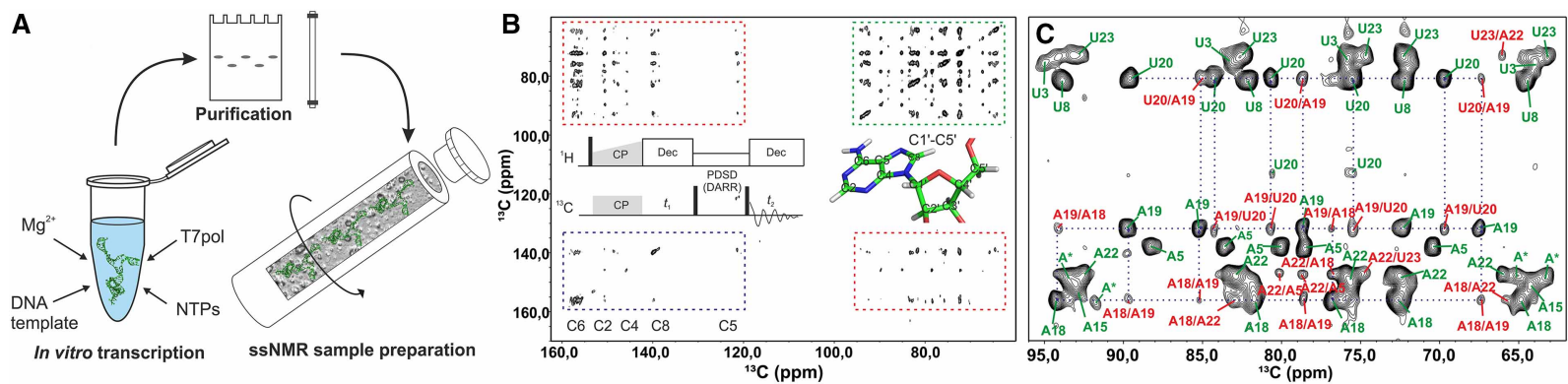

Figure 1. Solid-state NMR for studies of RNA.

(A) Schematic representation of RNA synthesis, RNA purification and conditions optimization for ssNMR sample preparation. (B) $2 \mathrm{D}{ }^{13} \mathrm{C},{ }^{13} \mathrm{C}$ PDSD experiment together with its pulse sequence illustrated by a spectrum of ${ }^{13} \mathrm{C},{ }^{15} \mathrm{~N}$ labeled adenine ( $\mathrm{A}^{\text {lab }}$-) $26 \mathrm{mer}$ box $\mathrm{C} / \mathrm{D}$ RNA in complex with $\mathrm{L} 7 \mathrm{Ae}$ protein. The spectrum was acquired at $500 \mathrm{~ms}$ mixing time giving rise to a full set of intranucleotide carbon-carbon correlations. Ribose-ribose, base-base and ribose-base correlations are enclosed by green, blue and red rectangles, respectively. Adenine nucleotide with carbon nomenclature is shown. (C) Ribose region of $2 \mathrm{D}{ }^{13} \mathrm{C},{ }^{15} \mathrm{~N}$ TEDOR- ${ }^{13} \mathrm{C},{ }^{13} \mathrm{C}$ PDSD spectrum of nucleotide-type selectively labeled A, $U^{\text {lab }}$-RNA. Due to long PDSD mixing time both intra- and inter-nucleotide peaks were observed, which are labeled in green and red, respectively. Selected inter-nucleotide correlations are highlighted. (B) is reprinted from [36] @ (2019) with permission from Elsevier. (C) is reprinted from [46]. 
solution-state directly into ssNMR rotor using an ultracentrifuge [31,32]. This approach shows very promising results for studies of protein assemblies [33], and recently it was applied to a ribosomal subunit 50S in complex with a trigger factor [34]. However, this method has not yet been tested for any labeled RNA containing biomolecular complexes.

\section{Protocol for RNA structure determination by solid-state NMR spectroscopy}

Aiming for de novo structure of RNA without any available prior structural information, a conventional protocol of RNA structure determination by NMR must be applied. The procedure requires: (a) unambiguous assignment of resonances, followed by (b) acquisition of distance and dihedral restraints, finalized by (c) structural calculations that provide RNA structure [35,36]. Next, we will briefly outline our ssNMR workflow for RNA structure determination (Figure 1). Please refer to our recent work for a detailed protocol [36].

Assignment of resonances in RNA is a challenging task due to severely overlapped signals of most ribose and base atoms. This task can be divided into intranucleotide assignment (spin-system assignment and identification) and internucleotide (sequential) assignment (connection of spin systems). Assignment strategy in ssNMR is quite different from that in solution-state NMR due to the preservation of dipolar couplings and typically applied ${ }^{13} \mathrm{C}$ detection in conventional ssNMR. In most cases, nucleotide-type selective labeling is necessary to overcome severe resonance overlap. Ribose carbons could be correlated through homonuclear ${ }^{13} \mathrm{C},{ }^{13} \mathrm{C}$ correlation experiments like symmetry-based recoupling [37], PDSD [38], DARR [39] or novel PAR [40] experiments; intranucleotide ribose-base connections could be obtained through PDSD correlation as well utilizing longer mixing time (Figure 1B). In ${ }^{13} \mathbf{C}^{13} \mathbf{C}$ PDSD experiment after initial cross-polarization (CP) from ${ }^{1} \mathrm{H}$ to ${ }^{13} \mathrm{C},{ }^{13} \mathrm{C}$ chemical shifts are evolved during $t_{1}$. Following, ${ }^{13} \mathrm{C}$ magnetization is spread over ribose and base carbons during PDSD or DARR and then detected during $t_{2}$. We have utilized PDSD correlation scheme to obtain preliminary assignment of carbons in the $26 \mathrm{mer}$ box C/D RNA from Pyrococcus furiosis (Pf) (Figure 3G); this experiment is equally efficient for nucleotide-type labeled $72 \mathrm{nt}$ long RNA part of $370 \mathrm{kDa}$ large box C/D RNP complex [8]. More sophisticated heteronuclear 3D CNC experiment [41] greatly reduces resonance overlap, provides the information on nucleotide type and delivers ribose-base correlations. The experiment contains two specific- $\mathrm{CP}$ [42] steps and correlates ribose $\mathrm{C1}^{\prime}$ carbon with base $\mathrm{C} 2, \mathrm{C} 6 / \mathrm{C} 4, \mathrm{C} 8$ carbons via nitrogen atom N1/N9 in purines and pyrimidines, respectively (Figure 2). In principle, using just two double-nucleotide-type selective labeled samples (e.g. ${ }^{13} \mathrm{C},{ }^{15} \mathrm{~N}-\mathrm{A}, \mathrm{U}^{\text {lab }}$-RNA and ${ }^{13} \mathrm{C},{ }^{15} \mathrm{~N}-\mathrm{G}, \mathrm{C}^{\text {lab }}-\mathrm{RNA}$ ) complete identification of all spin systems and complete intranucleotide assignment of ribose-base connectivities are possible.

Alternatively to previously discussed CNC experiment, ${ }^{13} \mathbf{C},{ }^{15} \mathbf{N}$ TEDOR experiment $[43,44]$ coupled with ${ }^{13} \mathrm{C},{ }^{13} \mathrm{C}$ PDSD step can be applied to correlate ribose and base carbons with $\mathrm{N} 1$ and N9 nitrogens in pyrimidines and purines, respectively (Figures $1 \mathrm{C}$ and 2 ). This experiment was successfully implemented by Görlach group in their studies of (CUG) $)_{97}$ RNA repeat [45] and then used by us in the assignment of resonances in the 26mer box C/D RNA both ambiguously [41] and sequentially [46].

Assignment of base nitrogen resonances is a more challenging task, but this step is crucial for the determination of base pairing patterns and the acquisition of inter-nucleotide distance restraints. Fortunately, ${ }^{13} \mathrm{C}$ detection and strong dipolar couplings in conventional ssNMR overcome the disadvantage of low density of protons in the base, which typically represents a serious challenge in solution-state NMR. In an illustrative NCC experiment on RNA bases [41] magnetization is transferred from protonated imino or amino nitrogens to directly attached carbons by specific-CP [42]. Consequent PDSD or DARR step can spread magnetization up to $\mathrm{Cl}^{\prime}$ providing a better assignment (Figure 2).

Recently fast magic angle spinning $(>100 \mathrm{kHz})$ probes have become available, which allows to perform ${ }^{1} \mathrm{H}$-detected ssNMR studies of protonated uniformly ${ }^{13} \mathrm{C},{ }^{15} \mathrm{~N}$ labeled proteins $[49,50]$. In collaboration with Pintacuda group we have developed a set of ${ }^{1} \mathrm{H}$-detected $3 \mathrm{D}$ and $4 \mathrm{D}$ experiments and applied them for the study of uniformly ${ }^{13} \mathrm{C},{ }^{15} \mathrm{~N}$ labeled 26 mer box C/D RNA [51]. These experiments resulted in almost complete assignment of ribose resonances, greatly reducing preparative efforts and experimental time.

While the sequential assignment of proteins by ssNMR is straightforward and can be accomplished by combination of 3D NCACX, NCOCX and CONCA experiments [52,53], sequential assignment of RNA is not 


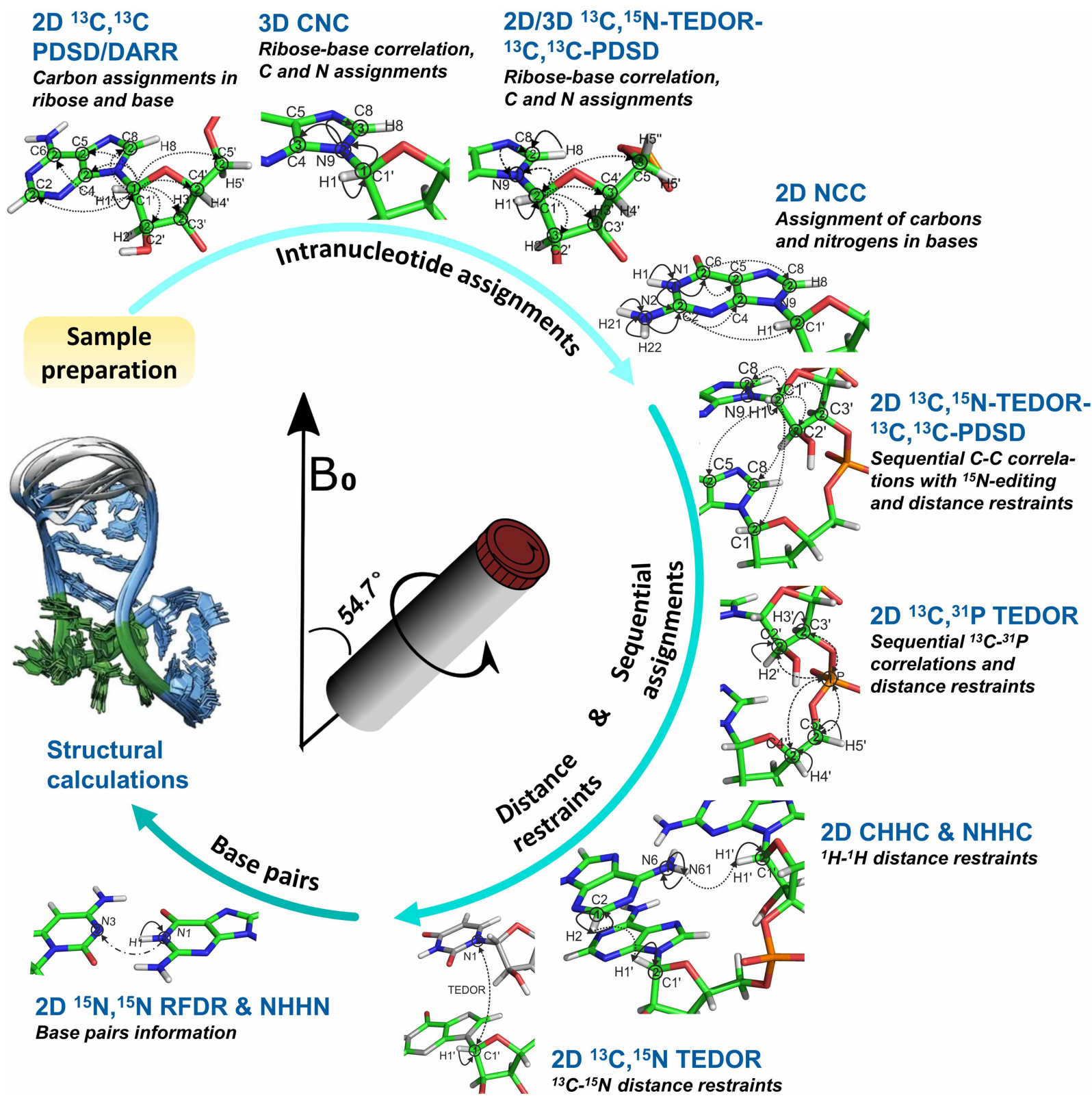

Figure 2. Representative solid-state NMR experiments in the RNA structure determination workflow.

ssNMR experiments for the intranucleotide [41] and sequential assignments are shown as well as experiments for measurements of distance restraints and base pairs patterns [36,46]. See text for details. In magnetization transfer schemes solid arrows indicate the CP or specific-CP [42] transfers; the dotted arrows indicate PDSD [38]/DARR [39] transfers or proton spin diffusion [47]; dashed arrows indicate TEDOR [43] transfer; dash-dotted arrows indicate ${ }^{15} \mathrm{~N},{ }^{15} \mathrm{~N}$ RFDR transfers [48]; arabic numbers correspond to the spectral dimensions of 2D or 3D spectra. Magnetization transfer schemes are reprinted from [36] () (2019) with permission from Elsevier. ssNMR structure of the 26mer box C/D RNA is adapted from [46].

simple due to absence of one-bond connectivities. Sequential assignment of RNA in solution-state NMR uses sequential ribose-base NOEs or heavily overlapped $\mathrm{C}_{\text {ribose }}-\mathrm{P}$ correlations [35,54]; we have proposed similar approach for ssNMR of RNA [46].

First successful attempts to acquire inter-nucleotide correlations and obtain sequential distance restraints in RNA were performed by Görlach group in their study on (CUG) ${ }_{97}$ RNA repeat (Figure 3A); there homonuclear CHHC experiment [47] acquired at different mixing times has provided sequential C2'-C6 correlations [55] 
(Figure 3B,C). Additionally, they were able to acquire $\mathrm{CHHC} / \mathrm{NHHN} / \mathrm{CHHN}$ and NHHC datasets in a single experiment using the multi-receiver capability of their spectrometer [56]. We have implemented similar approach in our study of the 26 mer box C/D RNA using long-range ${ }^{13} \mathrm{C},{ }^{13} \mathrm{C}$ PDSD (Figures $1 \mathrm{~B}$ and 2) as sequential correlation step [46]. Due to significant signal overlap, resolution of homonuclear ${ }^{13} \mathrm{C},{ }^{13} \mathrm{C}$ correlation experiments would not be sufficient, so we have coupled ${ }^{13} \mathrm{C}^{13} \mathrm{C}$ PDSD with heteronuclear editing ${ }^{13} \mathrm{C},{ }^{15} \mathrm{~N}$-TEDOR [43] block to reduce spectral overlap. Double-nucleotide-type specific labeling was necessary to perform sequential assignment. TEDOR spectrally separates purines and pyrimidines in double-nucleotide-type selective labeled samples and allows identification of hidden/overlapped weak internucleotide peaks (Figure 1C).

Furthermore, we have also explored the applicability of $\mathrm{C}_{\text {ribose }}-\mathrm{P}$ correlations for studies of RNA by ssNMR. ${ }^{13} \mathrm{C},{ }^{31} \mathbf{P}$ TEDOR experiment has provided $\mathrm{C} 2{ }^{\prime}{ }_{i}-\mathrm{P}_{\mathrm{i}+1}$ and $\mathrm{C} 3^{\prime}{ }_{\mathrm{i}}-\mathrm{P}_{\mathrm{i}+1}$ correlations (Figure 2). Unfortunately, ${ }^{31} \mathrm{P}$ resonances were poorly resolved in helices and sequential contacts were obtained only for non-canonical structural elements (kink-turn) [46]. Altogether, using nucleotide-type selective labeling we could assign more than $80 \%$ of site specific ${ }^{13} \mathrm{C}$ and ${ }^{15} \mathrm{~N}$ resonances for the box C/D 26mer RNA [46]. The availability of an RNA production platform (solid-phase synthesis) can significantly facilitate the sequence-specific assignment. We have explored this approach in collaboration with Kreutz group by utilization of C8/C6 atom-specific labeling of guanines and uraciles, which provided us with some sequential base-base correlations [8]. Most certainly, proton-detected ssNMR with its superior resolution and sensitivity will provide sequential correlations in similar manner to solution-state NMR experiment and additionally benefit from sensitive dipolar transfer schemes in ssNMR.

Most of the correlations utilized for the sequential assignment are used to derive distance restraints. More distance restraints can be obtained from TEDOR [43], PAR [40], CHHC [47] and NHHC [57] experiments. However, 2D ${ }^{13} \mathrm{C},{ }^{13} \mathrm{C}$ correlation spectra, which are sufficient for structural studies of uniformly labeled proteins $[2,3,58]$, might not provide sufficient spectral resolution even for nucleotide-type selective labeled RNA. In our study of the 26 mer box C/D RNA we have used long-range ${ }^{13} \mathrm{C},{ }^{13} \mathrm{C}$ PDSD correlation coupled with ${ }^{13} \mathrm{C},{ }^{15} \mathrm{~N}$ TEDOR block to obtain resonance assignment and long-range carbon-carbon distance restraints. CHHC and NHHC experiments (Figure 2) delivered several useful $\mathrm{H}-\mathrm{H}$ restraints. Furthermore, we have obtained $\mathrm{C}-\mathrm{P}$ and $\mathrm{C}-\mathrm{N}$ distance restraints from ${ }^{13} \mathrm{C},{ }^{31} \mathrm{P}$ and ${ }^{13} \mathrm{C},{ }^{15} \mathrm{~N}$ TEDOR experiments, respectively (Figure 2). In principle, experiments like TEDOR [43] or RFDR [48] could provide precise distance restraints by analysis of the polarization transfer trajectories in Simpson [59] or Spinach [60]. However, due to sensitivity reasons, we have converted inter-nucleotide correlations into non-precise distance restraints instead.

Information about base pairing pattern is a prerequisite for the structure determination of RNA by NMR. Görlach group was the first to demonstrate the presence of WC base pairs in (CUG) $)_{97}$ RNA repeat (Figure 3A) by observing G-N1/C-N3 cross-peaks via direct N-N homonuclear correlation experiment [22] or by observing G-N1/C-N4 correlation in NHHN-type experiment [61]. In our study of the 26mer box C/D RNA we have followed the same approach and applied ${ }^{15} \mathbf{N},{ }^{15} \mathrm{~N}$ RDFR [48] experiment to obtain A-N1/U-N3 and G-N1/C-N3 correlations that indicated the presence of WC base pairs (Figure 2). Recently, a novel method has been suggested by Wang group, where the long range ${ }^{15} \mathrm{~N},{ }^{15} \mathrm{~N}$ PAR transfer coupled with proton detection was applied to obtain inter-nucleotide C-N3/G-H1 and A-N1/U-H3 correlations from 2D hCN(PAR)NH experiment [62]. In their study PAR has allowed efficient inter-base transfer while ${ }^{1} \mathrm{H}$-detection has significantly increased sensitivity.

Dihedral angles, which can be directly measured through homonuclear ${ }^{3} \mathrm{~J}(\mathrm{H}, \mathrm{H})$ coupling constants in liquidstate NMR of RNA [35] are currently out of reach for state-of-the-art ssNMR. However, indirect estimation of ribose conformation can be obtained from ribose chemical shifts. This approach was proposed by Ebrahimi et al. in solution-state NMR [63], confirmed by Görlach group [37], advanced by Schwalbe group in their study of 14mer model RNA [64] and then implemented by us in the study of the 26mer box C/D RNA [46]. Information about ribose conformation allows to identify secondary structure elements and provides valuable dihedral restraints for structure determination.

All collected distance restraints, base pair- and dihedral angle restraints can be used in any software package of choice like ARIA [65], CYANA [66], XPLOR-NIH [67] or Haddock [68] to perform structural calculations. In our study of the $26 \mathrm{mer}$ box C/D RNA we have utilized 206 distance restraints and 174 dihedral restraints in ARIA package to calculate the structure of RNA with precision of $0.9 \AA$ (Figure 2). 


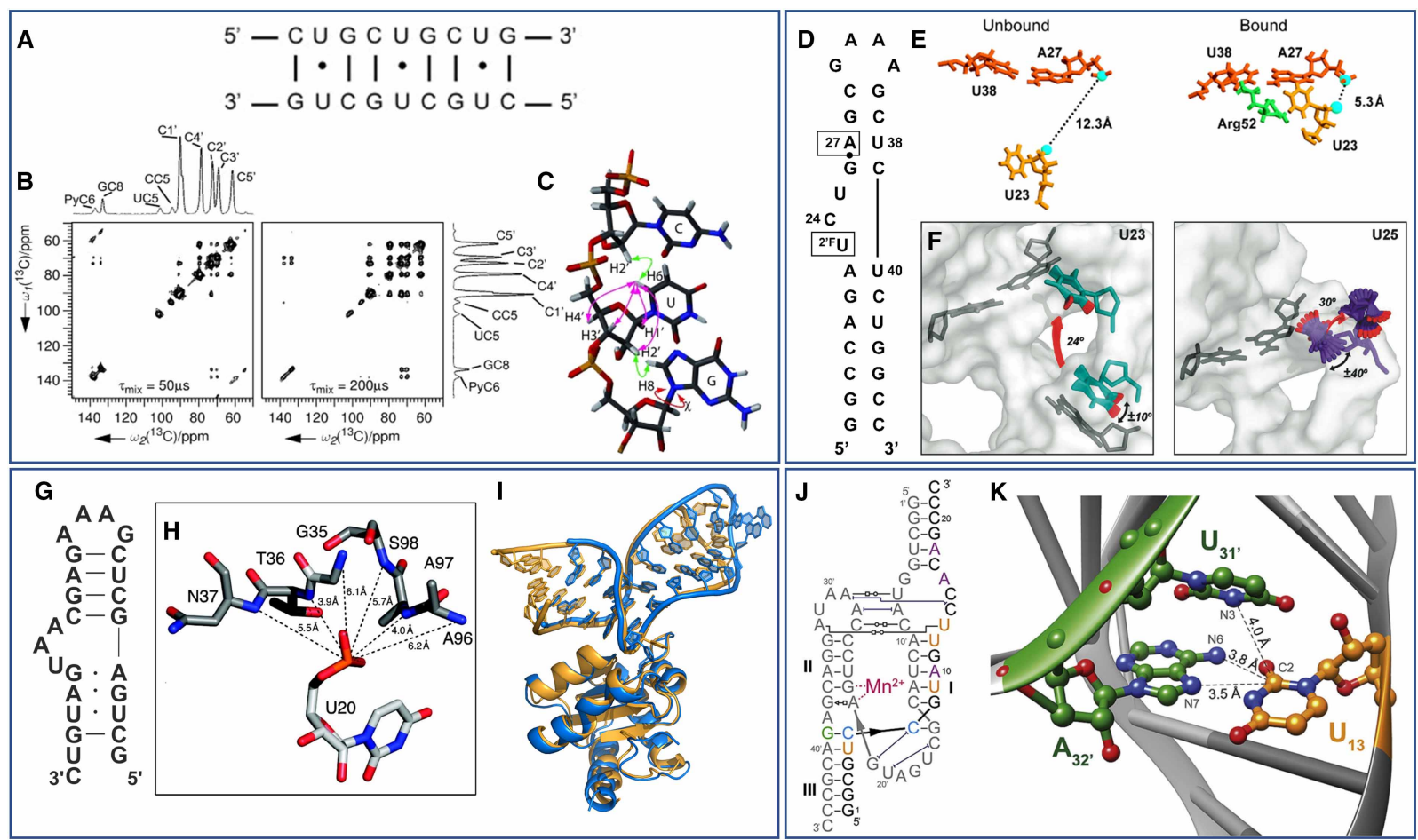

Figure 3. Important structural studies of RNAs and RNPs by ssNMR.

(A-C) Double-stranded (CUG) $)_{97}$ RNA repeat. (A) Schematic representation of (CUG) 97 RNA. (B) Experimental ${ }^{13} \mathrm{C},{ }^{13} \mathrm{C}$ chemical shift correlation spectra of the hydrated uniformly $\left[{ }^{15} \mathrm{~N},{ }^{13} \mathrm{C}\right]$-labeled $(\mathrm{CUG})_{97}$ RNA acquired with different mixing times. Assignments of the different resonances are indicated. (C) Intra- and inter-nucleotide ${ }^{1} \mathrm{H}-{ }^{1} \mathrm{H}$ dipolar interactions in a double-stranded A-form helical RNA, only one strand of the RNA is shown. (Figures (A-C) are adapted from [55] with permission from John Wiley and Sons@ 2006). (D-F) TAR RNA-Tat complex. (D) Sequence of TAR RNA with indicated specific labeling at positions U23 and A27. (E) Rearrangement of the TAR-RNA binding site on Tat-derived peptide binding. Blue spheres represent ${ }^{19} \mathrm{~F}$ and pS labels at positions $\mathrm{U} 23$ and $\mathrm{A} 27$, respectively. The ${ }^{19} \mathrm{~F}-\mathrm{pS}$ distance decreases from 12.3 to $5.3 \mathrm{~A}^{\circ}$ on Tat binding. (Figures (D-E) are reprinted from [18]). (F) The motions of nucleotides U23 (left) and U25 (right) in TAR RNA studied by ${ }^{2} \mathrm{H}$-ssNMR spectroscopy. Selective deuterated sites are indicated in red. See the text for details. (Reprinted with permission from [73] () (2010) American Chemical Society). (G-I) 26mer box C/D RNA-L7Ae protein complex from Pf. (G) Sequence and secondary structure of the 26mer box C/D RNA. (H) Distances between the L7Ae protein backbone ${ }^{15} \mathrm{~N}$ nuclei and the U20- ${ }^{31} \mathrm{P}$ nuclei in kink-turn $26 \mathrm{mer}$ box C/D RNA binding site measured based on TEDOR experiments (Reprinted with permission from [28] () (2010) American Chemical Society). (I) Overlay of ssNMR-derived structure of L7Ae-26mer box C/D RNP (blue, PDB ID 6TPH) with the crystallographic structure of the orthologous L7Ae-RNA complex from A. fulgidus (gold, PDB ID 4BW0 [69]). (Reproduced from [76]). (J-K) DNP ssNMR study of hybridized hammerhead ribozyme (HHRz). (J) Secondary structure of the HHRz construct depicting ${ }^{13} \mathrm{C}$-labeled uridines (yellow), adenosines (purple) and $\mathrm{Mn}^{2+}$ binding site (pink). (K) Tertiary (inter-stem) contact between $\mathrm{U} 13$ (orange) and A32' (green) formed by reverse Hoogsteen base pairing, including neighboring U31' (green). Distances as extracted from the crystal structure PDB ID 2OEU [70] are given for observed contacts by TEDOR experiment. (Reprinted from [25] @2019 with permission from Elsevier).

\section{Structural and functional studies of RNA and protein-RNA complexes by ssNMR}

The above presented ssNMR protocol opens the path for structural studies of RNA by ssNMR. However, if sitespecific labeled RNA is available or the RNA molecule of interest is small, the resonance assignment of RNA is not required due to prior knowledge of nucleotide positions. Then, direct measurements of structural or dynamic data are possible. This approach typically requires (a) access to sophisticated synthesis platform (solidphase synthesis etc.) and (b) can be practically applied only to short RNAs. This concept was successfully implemented by Drobny group in their study of HIV TAR-RNA (Figure 3D) and its complex with the viral regulatory protein Tat. In their pioneer study, they have incorporated specific labels in TAR RNA at positions $\mathrm{U} 23\left({ }^{19} \mathrm{~F}\right)$ and A27 (phosphorothioate, pS) and utilized ${ }^{31} \mathrm{P}-{ }^{19} \mathrm{~F}$ REDOR [71] spectroscopy to observe change 
in U23-A27 distances upon binding to the Tat peptide (Figure 3E) [18]. In the following studies, Arg52 in Tat peptide was additionally ${ }^{13} \mathrm{C},{ }^{15} \mathrm{~N}$ labeled which allowed to perform intermolecular TAR-Tat ${ }^{19} \mathrm{~F}-{ }^{13} \mathrm{C} /{ }^{19} \mathrm{~F}-{ }^{15} \mathrm{~N} /{ }^{31} \mathrm{P}-{ }^{13} \mathrm{C} /{ }^{31} \mathrm{P}-{ }^{15} \mathrm{~N}$ REDOR experiments $[19,72]$. Measured intermolecular distances resulted in the detailed model of the TAR-Tat complex that is in good agreement with solution-state NMR derived structure.

Not only structure, but also the dynamics of RNA can be studied by ssNMR. The only research lab currently studying RNA dynamics by ssNMR is the Drobny group. They have performed selective deuteration at positions H5 and H6 in uridines U23, U25 and U38 in TAR RNA and have applied ${ }^{2} \mathrm{H}$-ssNMR spectroscopy. First, they have shown that motions occurring at $\mu s-n s$ time scale can be analyzed by simulation of ${ }^{2} \mathrm{H}$ line shape [20]. Following, based on the analysis of the ${ }^{2} \mathrm{H}$ line shape both amplitudes and motion rates of residues within the TAR binding interface have been obtained [73]. The motions of non-helical nucleotide U23 can be described by a $24^{\circ}$ jump linking the conformation observed for this nucleotide in free TAR-RNA to its position observed in the TAR-RNA-Tat complex; in addition fast $\pm 11^{\circ}$ rotations of the base with respect to the sugar are observed. The motions of non-helical nucleotide U25 can be characterized as a combination of a slow $30^{\circ}$ outward jump and slower $\pm 40^{\circ}$ rotation about the glycosidic bond (Figure $3 \mathrm{~F}$ ). Motions of nucleotide U38 in helix can be characterized by combination of $13^{\circ}$ twisting and $13^{\circ}$ bending corresponding to the cooperative movement of the entire upper helix with rate of $\sim 10^{6} \mathrm{~s}^{-1}$ [73]. Very recently they have additionally measured motion rates for nucleotides $\mathrm{U} 40$ and $\mathrm{U} 42$ in lower helix, which appear to be much slower $\left(\sim 10^{5} \mathrm{~s}^{-1}\right)$ than those in the upper helix, indicating that two helical domains reorient independently of one another [74].

Similarly, assignment and structure determination of RNA are not necessary, if prior information about the structural arrangement of the protein-RNA complex is available from the comparison with heterologous complexes. This approach has been utilized by Carlomagno group to characterize the protein-RNA interface in L7Ae-box C/D 26mer RNA complex (Figure 3G). It was assumed that only one nucleotide (U20) is in close vicinity to the protein backbone. In their study L7Ae protein was uniformly ${ }^{15} \mathrm{~N}$ labeled; six precise ${ }^{31} \mathrm{P}-{ }^{15} \mathrm{~N}$ distances (Figure 3H) were measured by analysis of TEDOR build-up curves between protein backbone nitrogens and phosphorus in the nucleotide U20 [28]. Different approach has been implemented by Reif and Carlomagno groups in the ${ }^{1} \mathrm{H}$-detected ssNMR study of the same protein-RNA complex. Here, by analysis of the reduction of ${ }^{1} \mathrm{H}-{ }^{15} \mathrm{~N}$ L7Ae resonances in close proximity to protonated $26 \mathrm{mer}$ box $\mathrm{C} / \mathrm{D}$ RNA quantitative distance restraints up to $6 \AA$ were obtained [75].

On the opposite, in recent contribution from our and Carlomagno group, only ssNMR data without any preliminary information about the relative arrangement of protein and RNA have been used to obtain first de novo structure of protein-RNA complex [76]. In this study, we have refrained from usage of long-range dipolar magnetization transfer due to (a) considerable overlap of resonances and (b) significant attenuation of the signal in non-specific labeled samples due to dipolar truncation [77]. Instead, we have developed the method that uses intermolecular paramagnetic relaxation enhancement (PRE) and chemical shift perturbation (CSP) on protein upon RNA binding [76]. PRE effect utilizes strong dipolar interactions between nuclei and unpaired electrons that leads to increased relaxation rates of nuclei and therefore signal attenuation [78]. In ssNMR PREs were first used in studies from Emsley laboratory [79] and Jaroniec laboratory [80,81]. In our study, we have developed a semi-quantitative approach, where PRE effect is observed on RNA resonances in complex with paramagnetic spin-label tagged protein. Intra-protein PREs on protein with known 3D structure are used to derive a PRE ruler, which is then used to obtain intermolecular protein-RNA restraints from intermolecular PREs. Combining these restraints and protein CSPs in Haddock [68] we have obtained ssNMR-derived structure of L7Ae-box C/D 26mer RNA complex with $1.7 \AA$ precision (Figure 3I) [76].

Unique features of unpaired electrons could be also very helpful in other techniques. In DNP, the large electron spin polarization of a paramagnetic polarizing agent is transferred to nuclear spins and increases the sensitivity of the NMR experiment by several orders of magnitude [49,82-84]. Application of the hyperpolarization technique on RNA and RNP is still at the early stages of development but it holds great promises. For instance, Baldus group has applied DNP ssNMR to study cellular preparations and have acquired first spectra of RNA by DNP, identifying few intra- and intermolecular contacts [85]. Corzilius group applied DNP to a paramagnetic hammerhead ribozyme (HHRz) complex with endogenously bound $\mathrm{Mn}^{2+}$ and obtained eight times ${ }^{13} \mathrm{C}$ signal enhancement [24]. A 160-200 fold signal enhancement was observed when 5 mM AMUpol was used in a nucleotide specific and also orthogonally labeled $\mathrm{HHRz}$ [25]. In this study using a DNP-enhanced ${ }^{13} \mathrm{C}$, ${ }^{13} \mathrm{C}$ PDSD and ${ }^{13} \mathrm{C},{ }^{15} \mathrm{~N}$ TEDOR, specific investigation of relevant inter-strand and/or inter-stem contacts was performed and a non-canonical reverse Hoogsteen base pairing was discovered (Figure 3J-K). Recently, Corzilius 
group have discovered a SCREAM-DNP (specific cross-relaxation enhancement by active motions) effect [86]. Polarization transfer during SCREAM is mediated by ${ }^{1} \mathrm{H}^{13} \mathrm{C}$ cross-relaxation within methyl groups due to reorientation dynamics, and results in an enhanced and inverted ${ }^{13} \mathrm{C}$ NMR signal. This approach allows to spectrally isolate the complex from the unbound mixture. In their recent study, SCREAM-DNP was instrumental to provide insights into the molecular structure of RNA aptamer-selectively methyl-labeled tetracycline complex [26].

\section{Perspectives}

- RNA and RNPs are key players in numerous cellular activities, understanding their action mechanisms requires structural knowledge. ssNMR is a novel alternative structural biology method that can provide structural information at the atomic level of precision for large conformationally flexible biomolecules.

- Despite significant challenges in studying RNA and RNP by ssNMR, compelling progress has been achieved in the last decade both in methodology development as well as applications, thus opening the way to study large RNAs.

- Now and in the future, the quest to explore structure and dynamics of RNA in large molecular machines by ssNMR is continuously supported by advances in sample preparation (specific and segmental labeling), spectrometer hardware development (high-field magnets and new probes), new techniques (DNP) and concepts (proton detection and multi-receiver detection) and new approaches for spectra acquisition and processing (non-uniform sampling).

\section{Competing Interests}

The authors declare that there are no competing interests associated with the manuscript.

\section{Acknowledgements}

A.K.S. was supported by the DFG grant MA5157/3-1 to A.M.

\section{Abbreviations}

ARIA, ambiguous restraints for iterative assignment; CP, cross-polarization; CSP, chemical shift perturbation; DARR, dipolar assisted rotational resonance; DNA, deoxy ribonucleic acid; DNP, dynamic nuclear polarization; EM, electron microscopy; HHRz, hammerhead ribozyme; HPLC, high-performance liquid chromatography; MAS, magic angle spinning; NMR, nuclear magnetic resonance spectroscopy; NOE, nuclear Overhauser effect; PAGE, polyacrylamide gel electrophoresis; PAR, proton assisted recoupling; PDSD, proton driven spin diffusion; PEG, polyethylene glycol; PRE, paramagnetic relaxation enhancement; $p S$, phosphorothioate; RDFR, radio frequency driven recoupling; REDOR, rotational-echo double-resonance; RNA, ribonucleic acid; RNP, ribonucleoprotein; rNTP, ribonucleoside tri-phosphate; SCREAM, specific cross-relaxation enhancement by active motions; ssNMR, solid-state nuclear magnetic resonance spectroscopy; TAR, trans-activation response; TEDOR, transferred echo double resonance; WC, Watson-Crick.

\section{References}

1 Serganov, A. and Patel, D.J. (2007) Ribozymes, riboswitches and beyond: regulation of gene expression without proteins. Nat. Rev. Genet. 8, 776-790 https://doi.org/10.1038/nrg2172

2 Castellani, F., van Rossum, B., Diehl, A., Schubert, M., Rehbein, K. and Oschkinat, H. (2002) Structure of a protein determined by solid-state magic-angle-spinning NMR spectroscopy. Nature 420, 98-102 https://doi.org/10.1038/nature01070

3 Bertini, I., Bhaumik, A., De Paepe, G., Griffin, R.G., Lelli, M., Lewandowski, J.R. et al. (2010) High-resolution solid-state NMR structure of a $17.6 \mathrm{kDa}$ protein. J. Am. Chem. Soc. 132, 1032-1040 https://doi.org/10.1021/ja906426p

4 Loquet, A., El Mammeri, N., Stanek, J., Berbon, M., Bardiaux, B., Pintacuda, G. et al. (2018) 3D structure determination of amyloid fibrils using solid-state NMR spectroscopy. Methods (San Diego, Calif) 138-139, 26-38 https://doi.org/10.1016/j.ymeth.2018.03.014 
5 Mandala, V.S., Williams, J.K. and Hong, M. (2018) Structure and dynamics of membrane proteins from solid-state NMR. Annu. Rev. Biophys. 47, 201-222 https://doi.org/10.1146/annurev-biophys-070816-033712

6 Marchanka, A. and Carlomagno, T. (2014) Solid-state NMR and RNA structure: a new partnership? eMagRes 3, 119-128 https://doi.org/10.1002/ 9780470034590.emrstm1358

7 Yang, Y. and Wang, S. (2018) RNA characterization by solid-state NMR spectroscopy. Chemistry 24, 8698-8707 https://doi.org/10.1002/chem.201705583

8 Marchanka, A., Kreutz, C. and Carlomagno, T. (2018) Isotope labeling for studying RNA by solid-state NMR spectroscopy. J. Biomol. NMR 71, 151-164 https://doi.org/10.1007/s10858-018-0180-7

9 Reese, C.B. (2005) Oligo- and poly-nucleotides: 50 years of chemical synthesis. Org. Biomol. Chem. 3, 3851-3868 https://doi.org/10.1039/b510458k

10 Wunderlich, C.H., Spitzer, R., Santner, T., Fauster, K., Tollinger, M. and Kreutz, C. (2012) Synthesis of (6-C-13)pyrimidine nucleotides as spin-labels for RNA dynamics. J. Am. Chem. Soc. 134, 7558-7569 https://doi.org/10.1021/ja302148g

11 Juen, M.A., Wunderlich, C.H., Nussbaumer, F., Tollinger, M., Kontaxis, G., Konrat, R. et al. (2016) Excited states of nucleic acids probed by proton relaxation dispersion NMR spectroscopy. Angew. Chem. Int. Ed. 55, 12008-12012 https://doi.org/10.1002/anie.201605870

12 Beaucage, S.L. and Reese, C.B. (2009) Recent advances in the chemical synthesis of RNA. In Current Protocols in Nucleic Acid Chemistry (Egli, M., Herdewijn, P., Matsuda, A., Yogesh, S., Sanghvi, Y.S., eds), pp. 2.16.1-2.2.31, Wiley, New York, NY

13 Melton, D.A., Krieg, P.A., Rebagliati, M.R., Maniatis, T., Zinn, K. and Green, M.R. (1984) Efficient in vitro synthesis of biologically-active RNA and RNA hybridization probes from plasmids containing A bacteriophage-Sp6 promoter. Nucleic Acids Res. 12, 7035-7056 https://doi.org/10.1093/nar/12.18. 7035

14 Milligan, J.F. and Uhlenbeck, 0.C. (1989) Synthesis of small RNAs using T7 RNA-polymerase. Methods Enzymol. 180, 51-62 https://doi.org/10.1016/ 0076-6879(89)80091-6

15 Nikonowicz, E.P., Sirr, A., Legault, P., Jucker, F.M., Baer, L.M. and Pardi, A. (1992) Preparation of C-13 and N-15 labeled RNAs for heteronuclear multidimensional NMR-studies. Nucleic Acids Res. 20, 4507-4513 https://doi.org/10.1093/nar/20.17.4507

16 Duss, O., Lukavsky, P.J. and Allain, F.H. (2012) Isotope labeling and segmental labeling of larger RNAs for NMR structural studies. In Isotope Labeling in Biomolecular NMR. Advances in Experimental Medicine and Biology (Attrea, H.S, ed.), pp. 121-144, Springer, Dordrecht

17 Wang, A.C., Kennedy, M.A., Reid, B.R. and Drobny, G.P. (1994) A solid-state H-2-NMR investigation of purine motion in A 12-base-pair RNA duplex. J. Magn. Reson. B 105, 1-10 https://doi.org/10.1006/jmrb.1994.1092

18 Olsen, G.L., Edwards, T.E., Deka, P., Varani, G., Sigurdsson, S.T. and Drobny, G.P. (2005) Monitoring tat peptide binding to TAR RNA by solid-state P-31-F-19 REDOR NMR. Nucleic Acids Res. 33, 3447-3454 https://doi.org/10.1093/nar/gki626

19 Huang, W., Varani, G. and Drobny, G.P. (2011) Interactions of protein side chains with RNA defined with REDOR solid state NMR. J. Biomol. NMR 51, 347-356 https://doi.org/10.1007/s10858-011-9573-6

20 Olsen, G.L., Echodu, D.C., Shajani, Z., Bardaro, M.F., Varani, G. and Drobny, G.P. (2008) Solid-state deuterium NMR studies reveal mu s-ns motions in the HIV-1 transactivation response RNA recognition site. J. Am. Chem. Soc. 130, 2896-2897 https://doi.org/10.1021/ja0778803

21 Olsen, G.L., Bardaro, M.F., Echodu, D.C., Drobny, G.P. and Varani, G. (2009) Hydration dependent dynamics in RNA. J. Biomol. NMR 45, 133-142 https://doi.org/10.1007/s10858-009-9355-6

22 Leppert, J., Urbinati, C.R., Häfner, S., Ohlenschläger, O., Swanson, M.S., Görlach, M. et al. (2004) Identification of NH ... N hydrogen bonds by magic angle spinning solid state NMR in a double-stranded RNA associated with myotonic dystrophy. Nucleic Acids Res. 32, 1177-1183 https://doi.org/10. 1093/nar/gkh288

23 Siemer, A.B., Huang, K.Y. and McDermott, A.E. (2012) Protein linewidth and solvent dynamics in frozen solution NMR. PLos One 7, e47242 https://doi. org/10.1371/journal.pone.0047242

24 Wenk, P., Kaushik, M., Richter, D., Vogel, M., Suess, B. and Corzilius, B. (2015) Dynamic nuclear polarization of nucleic acid with endogenously bound manganese. J. Biomol. NMR 63, 97-109 https://doi.org/10.1007/s10858-015-9972-1

25 Daube, D., Vogel, M., Suess, B. and Corzilius, B. (2019) Dynamic nuclear polarization on a hybridized hammerhead ribozyme: an explorative study of RNA folding and direct DNP with a paramagnetic metal ion cofactor. Solid State Nucl. Magn. Reson. 101, 21-30 https://doi.org/10.1016/j.ssnmr.2019. 04.005

26 Aladin, V., Vogel, M., Binder, R., Burghardt, I., Suess, B. and Corzilius, B. (2019) Complex formation of the tetracycline-binding aptamer investigated by specific cross-relaxation under DNP. Angew. Chem. Int. Ed. 58, 4863-4868 https://doi.org/10.1002/anie.201811941

27 Franks, W.T., Zhou, D.H., Wylie, B.J., Money, B.G., Graesser, D.T., Frericks, H.L. et al. (2005) Magic-angle spinning solid-state NMR spectroscopy of the beta 1 immunoglobulin binding domain of protein $\mathrm{G}(\mathrm{GB} 1)$ : $\mathrm{N}-15$ and $\mathrm{C}-13$ chemical shift assignments and conformational analysis. J. Am. Chem. Soc. 127, 12291-12305 https://doi.org/10.1021/ja044497e

28 Jehle, S., Falb, M., Kirkpatrick, J.P., Oschkinat, H., van Rossum, B.J., Althoff, G. et al. (2010) Intermolecular protein-RNA interactions revealed by 2D P-31-N-15 magic angle spinning solid-state NMR spectroscopy. J. Am. Chem. Soc. 132, 3842-3846 https://doi.org/10.1021/ja909723f

29 Huang, W., Bardaro, M.F., Varani, G. and Drobny, G.P. (2012) Preparation of RNA samples with narrow line widths for solid state NMR investigations. J. Magn. Reson. 223, 51-54 https://doi.org/10.1016/j.jmr.2012.07.018

30 Zhao, S., Yang, Y., Zhao, Y., Li, X., Xue, Y. and Wang, S. (2019) High-resolution solid-state NMR spectroscopy of hydrated non-crystallized RNA. Chem. Commun. 55, 13991-4 https://doi.org/10.1039/C9CC06552K

31 Bertini, I., Luchinat, C., Parigi, G., Ravera, E., Reif, B. and Turano, P. (2011) Solid-state NMR of proteins sedimented by ultracentrifugation. Proc. Natt. Acad. Sci. U.S.A. 108, 10396-9 https://doi.org/10.1073/pnas.1103854108

32 Boeckmann, A., Gardiennet, C., Hunkeler, A., Loquet, A., Pintacuda, G., Emsley, L. et al. (2009) Characterization of different water pools in solid-state NMR protein samples. J. Biomol. NMR 45, 319 https://doi.org/10.1007/s10858-009-9374-3

33 Wiegand, T., Lacabanne, D., Torosyan, A., Boudet, J., Cadalbert, R., Allain, F.H.-T. et al. (2020) Sedimentation yields long-term stable protein samples as shown by solid-state NMR. Front. Mol. Biosci. 7, 17 https://doi.org/10.3389/fmolb.2020.00017

34 Barbet-Massin, E., Huang, C.T., Daebel, V., Hsu, S.T.D. and Reif, B. (2015) Site-specific solid-state NMR studies of "Trigger Factor" in complex with the large ribosomal subunit 50S. Angew. Chem. Int. Ed. 54, 4367-4369 https://doi.org/10.1002/anie.201409393

35 Fürtig, B., Richter, C., Wöhnert, J. and Schwalbe, H. (2003) NMR spectroscopy of RNA. ChemBioChem 4, 936-962 https://doi.org/10.1002/cbic. 200300700 
36 Marchanka, A. and Carlomagno, T. (2019) Chapter Nine - Solid-State NMR Spectroscopy of RNA. In Methods Enzymol (Wand, A.J., ed.), pp. 333-371 Academic Press, Cambridge

37 Riedel, K., Leppert, J., Häfner, S., Ohlenschläger, O., Görlach, M. and Ramachandran, R. (2004) Homonuclear chemical shift correlation in rotating solids via RNnv symmetry-based adiabatic RF pulse schemes. J. Biomol. NMR 30, 389-395 https://doi.org/10.1007/s10858-004-4056-7

38 Szeverenyi, N.M., Sullivan, M.J. and Maciel, G.E. (1982) Observation of spin exchange by two-dimensional Fourier-transform C-13 cross polarization-magic-angle spinning. J. Magn. Reson. 47, 462-475 https://doi.org/10.1016/0022-2364(82)90213-X

39 Takegoshi, K., Nakamura, S. and Terao, T. (2001) C-13-H-1 dipolar-assisted rotational resonance in magic-angle spinning NMR. Chem. Phys. Let. 344 631-637 https://doi.org/10.1016/S0009-2614(01)00791-6

40 De Paëpe, G., Lewandowski, J.R., Loquet, A., Bockmann, A. and Griffin, R.G. (2008) Proton assisted recoupling and protein structure determination. J. Chem. Phys. 129, $245101 \mathrm{https}: / /$ doi.org/10.1063/1.3036928

41 Marchanka, A., Simon, B. and Carlomagno, T. (2013) A suite of solid-state NMR experiments for RNA resonance assignment in a 21 kDa protein-RNA complex. Angew. Chem. Int. Ed. 52, 9996-10001 https://doi.org/10.1002/anie.201304779

42 Baldus, M., Petkova, A.T., Herzfeld, J. and Griffin, R.G. (1998) Cross polarization in the tilted frame: assignment and spectral simplification in heteronuclear spin systems. Mol. Phys. 95, 1197-1207 https://doi.org/10.1080/00268979809483251

43 Jaroniec, C.P., Filip, C. and Griffin, R.G. (2002) 3D TEDOR NMR experiments for the simultaneous measurement of multiple carbon-nitrogen distances in uniformly C-13, N-15-labeled solids. J. Am. Chem. Soc. 124, 10728-10742 https://doi.org/10.1021/ja026385y

44 Hing, A.W., Vega, S. and Schaefer, J. (1992) Transferred-echo double-resonance NMR. J. Magn. Reson. 96, 205-209 https://doi.org/10.1016/ 0022-2364(92)90305-Q

45 Riedel, K., Leppert, J., Ohlenschläger, 0., Görlach, M. and Ramachandran, R. (2005) TEDOR with adiabatic inversion pulses: Resonance assignments of C-13/N-15 labelled RNAs. J. Biomol. NMR 31, 49-57 https://doi.org/10.1007/s10858-004-6066-x

46 Marchanka, A., Simon, B., Althoff-Ospelt, G. and Carlomagno, T. (2015) RNA structure determination by solid-state NMR spectroscopy. Nat. Commun. 6, 7024 https://doi.org/10.1038/ncomms8024

47 Lange, A., Luca, S. and Baldus, M. (2002) Structural constraints from proton-mediated rare-spin correlation spectroscopy in rotating solids. J. Am. Chem. Soc. 124, 9704-9705 https://doi.org/10.1021/ja026691b

48 Bennett, A.E., Ok, J.H., Griffin, R.G. and Vega, S. (1992) Chemical-shift correlation spectroscopy in rotating solids - radio frequency-driven dipolar recoupling and longitudinal exchange. J. Chem. Phys. 96, 8624-8627 https://doi.org/10.1063/1.462267

49 Su, Y.C., Andreas, L. and Griffin, R.G. (2015) Magic angle spinning $\mathrm{nmr}$ of proteins: high-frequency dynamic nuclear polarization and H-1 detection. Ann. Rev. Biochem. 84, 465-497 https://doi.org/10.1146/annurev-biochem-060614-034206

50 Andreas, L.B., Jaudzems, K., Stanek, J., Lalli, D., Bertarello, A., Le Marchand, T. et al. (2016) Structure of fully protonated proteins by proton-detected magic-angle spinning NMR. Proc. Natl. Acad. Sci. U.S.A. 113, 9187-9192 https://doi.org/10.1073/pnas.1602248113

51 Marchanka, A., Stanek, J., Pintacuda, G. and Carlomagno, T. (2018) Rapid access to RNA resonances by proton-detected solid-state NMR at $>100 \mathrm{kHz}$ MAS. Chem. Commun. 54, 8972-8975 https://doi.org/10.1039/C8CC04437F

52 Zhong, L., Bamm, V.V., Ahmed, M.A.M., Harauz, G. and Ladizhansky, V. (2007) Solid-state NMR spectroscopy of 18.5 kDa myelin basic protein reconstituted with lipid vesicles: spectroscopic characterisation and spectral assignments of solvent-exposed protein fragments. Biochim. Biophys. Acta 1768, 3193-3205 https://doi.org/10.1016/.jbbamem.2007.08.013

53 Schuetz, A., Wasmer, C., Habenstein, B., Verel, R., Greenwald, J., Riek, R. et al. (2010) Protocols for the sequential solid-state NMR spectroscopic assignment of a uniformly labeled 25 kDa protein: HET-s(1-227). ChemBioChem 11, 1543-1551 https://doi.org/10.1002/cbic. 201000124

54 Wijmenga, S.S. and van Buuren, B.N.M. (1998) The use of NMR methods for conformational studies of nucleic acids. Prog. Nucl. Magn. Reson. Spectrosc. 32, 287-387 https://doi.org/10.1016/S0079-6565(97)00023-X

55 Riedel, K., Herbst, C., Häfner, S., Leppert, J., Ohlenschläger, O., Swanson, M.S. et al. (2006) Constraints on the structure of (CUG)(97) RNA from magic-angle-spinning solid-state NMR spectroscopy. Angew. Chem. Int. Ed. 45, 5620-5623 https://doi.org/10.1002/anie.200600769

56 Herbst, C., Riedel, K., Ihle, Y., Leppert, J., Ohlenschläger, O., Görlach, M. et al. (2008) MAS solid state NMR of RNAs with multiple receivers. J. Biomol. NMR 41, 121-125 https://doi.org/10.1007/s10858-008-9247-1

57 Lange, A., Seidel, K., Verdier, L., Luca, S. and Baldus, M. (2003) Analysis of proton-proton transfer dynamics in rotating solids and their use for 3D structure determination. J. Am. Chem. Soc. 125, 12640-8 https://doi.org/10.1021/ja034555g

58 Manolikas, T., Herrmann, T. and Meier, B.H. (2008) Protein structure determination from C-13 spin-diffusion solid-state NMR spectroscopy. J. Am. Chem. Soc. 130, 3959-3966 https://doi.org/10.1021/ja078039s

59 Bak, M., Rasmussen, J.T. and Nielsen, N.C. (2000) SIMPSON: a general simulation program for solid-state NMR spectroscopy. J. Magn. Reson. 147 296-330 https://doi.org/10.1006/jmre.2000.2179

60 Hogben, H.J., Krzystyniak, M., Charnock, G.T.P., Hore, P.J. and Kuprov, I. (2011) Spinach - a software library for simulation of spin dynamics in large spin systems. J. Magn. Reson. 208, 179-194 https://doi.org/10.1016/j.jmr.2010.11.008

61 Riedel, K., Leppert, J., Ohlenschläger, 0., Görlach, M. and Ramachandran, R. (2005) Characterisation of hydrogen bonding networks in RNAs via magic angle spinning solid state NMR spectroscopy. J. Biomol. NMR 31, 331-336 https://doi.org/10.1007/s10858-005-1614-6

62 Yang, Y., Xiang, S., Liu, X., Pei, X., Wu, P., Gong, Q. et al. (2017) Proton-detected solid-state NMR detects the inter-nucleotide correlations and architecture of dimeric RNA in microcrystals. Chem. Commun. 53, 12886-9 https://doi.org/10.1039/C7CC07483B

63 Ebrahimi, M., Rossi, P., Rogers, C. and Harbison, G.S. (2001) Dependence of C-13 NMR chemical shifts on conformations of RNA nucleosides and nucleotides. J. Magn. Reson. 150, 1-9 https://doi.org/10.1006/jmre.2001.2314

64 Cherepanov, A.V., Glaubitz, C. and Schwalbe, H. (2010) High-resolution studies of uniformly C-13,N-15-labeled RNA by solid-state NMR spectroscopy. Angew. Chem. Int. Ed. 49, 4747-4750 https://doi.org/10.1002/anie.200906885

65 Linge, J.P., Habeck, M., Rieping, W. and Nilges, M. (2003) ARIA: automated NOE assignment and NMR structure calculation. Bioinformatics 19, 315-316 https://doi.org/10.1093/bioinformatics/19.2.315

66 Güntert, P., Mumenthaler, C. and Wüthrich, K. (1997) Torsion angle dynamics for NMR structure calculation with the new program DYANA. J. Mol. Biol. 273, 283-298 https://doi.org/10.1006/jmbi.1997.1284 
67 Schwieters, C.D., Kuszewski, J.J., Tjandra, N. and Clore, G.M. (2003) The Xplor-NIH NMR molecular structure determination package. J. Magn. Reson. 160, 65-73 https://doi.org/10.1016/S1090-7807(02)00014-9

68 Dominguez, C., Boelens, R. and Bonvin, A.M.J.J. (2003) HADDOCK: a protein-protein docking approach based on biochemical or biophysical information. J. Am. Chem. Soc. 125, 1731-1737 https://doi.org/10.1021/ja026939x

69 Huang, L. and Lilley, D.M. (2013) The molecular recognition of kink-turn structure by the L7Ae class of proteins. RNA 19, 1703-1710 https://doi.org/10.1261/rna.041517.113

70 Martick, M., Lee, T.-S., York, D.M. and Scott, W.G. (2008) Solvent structure and hammerhead ribozyme catalysis. Chem. Biol. 15, 332-342 https://doi.org/10.1016/.j.chembiol.2008.03.010

71 Gullion, T. and Schaefer, J. (1989) Rotational-echo double-resonance NMR. J. Magn. Reson. 81, 196-200 https://doi.org/10.1016/0022-2364(89) 90280-1

72 Huang, W., Varani, G. and Drobny, G.P. (2010) C-13/N-15-F-19 intermolecular REDOR NMR study of the interaction of TAR RNA with Tat peptides. J. Am. Chem. Soc. 132, 17643-17645 https://doi.org/10.1021/ja1051439

73 Olsen, G.L., Bardaro, M.F., Echodu, D.C., Drobny, G.P. and Varani, G. (2010) Intermediate rate atomic trajectories of RNA by solid-state NMR spectroscopy. J. Am. Chem. Soc. 132, 303-308 https://doi.org/10.1021/ja907515s

74 Huang, W., Emani, P.S., Varani, G. and Drobny, G.P. (2017) Ultraslow domain motions in HIV-1 TAR RNA revealed by solid-state deuterium NMR J. Phys. Chem. B 121, 110-117 https://doi.org/10.1021/acs.jpcb.6b11041

75 Asami, S., Rakwalska-Bange, M., Carlomagno, T. and Reif, B. (2013) Protein-RNA interfaces probed by 1H-detected MAS solid-state NMR spectroscopy. Angew. Chem. Int. Ed. 52, 2345-2349 https://doi.org/10.1002/anie.201208024

76 Ahmed, M., Marchanka, A. and Carlomagno, T. (2020) Structure of a protein-RNA complex by ssNMR. Angew. Chem. Int. Ed. 59, 6866-6873 https://doi.org/10.1002/anie.201915465

77 Bayro, M.J., Huber, M., Ramachandran, R., Davenport, T.C., Meier, B.H., Ernst, M. et al. (2009) Dipolar truncation in magic-angle spinning NMR recoupling experiments. J. Chem. Phys. 130, 114506 https://doi.org/10.1063/1.3089370

78 Pell, A.J., Pintacuda, G. and Grey, C.P. (2019) Paramagnetic NMR in solution and the solid state. Prog. Nucl. Magn. Reson Spectrosc. 111, 1-271 https://doi.org/10.1016/j.pnmrs.2018.05.001

79 Pintacuda, G., Giraud, N., Pierattelli, R., Bockmann, A., Bertini, I. and Emsley, L. (2007) Solid-state NMR spectroscopy of a paramagnetic protein: assignment and study of human dimeric oxidized Cu-II-Zn-II superoxide dismutase (SOD). Angew. Chem. Int. Ed. 46, 1079-1082 https://doi.org/10. 1002/anie.200603093

80 Nadaud, P.S., Helmus, J.J., Hofer, N. and Jaroniec, C.P. (2007) Long-range structural restraints in spin-labeled proteins probed by solid-state nuclear magnetic resonance spectroscopy. J. Am. Chem. Soc. 129, 7502 https://doi.org/10.1021/ja072349t

81 Jaroniec, C.P. (2015) Structural studies of proteins by paramagnetic solid-state NMR spectroscopy. J. Magn. Reson. 253, 50-59 https://doi.org/10. 1016/j.jmr.2014.12.017

82 Hall, D.A., Maus, D.C., Gerfen, G.J., Inati, S.J., Becerra, L.R., Dahlquist, F.W. et al. (1997) Polarization-enhanced NMR spectroscopy of biomolecules in frozen solution. Science 276, 930-932 https://doi.org/10.1126/science.276.5314.930

83 Barnes, A.B., De Paëpe, G., van der Wel, P.C.A., Hu, K.N., Joo, C.G., Bajaj, V.S. et al. (2008) High-field dynamic nuclear polarization for solid and solution biological NMR. Appl. Magn. Reson. 34, 237-263 https://doi.org/10.1007/s00723-008-0129-1

84 Chakraborty, A., Deligey, F., Quach, J., Mentink-Vigier, F., Wang, P. and Wang, T. (2020) Biomolecular complex viewed by dynamic nuclear polarization solid-state NMR spectroscopy. Biochem. Soc. Trans. https://doi.org/10.1042/BST20191084

85 Renault, M., Pawsey, S., Bos, M.P., Koers, E.J., Nand, D., Tommassen-van Boxtel, R. et al. (2012) Solid-state NMR spectroscopy on cellular preparations enhanced by dynamic nuclear polarization. Angew. Chem. Int. Ed. 51, 2998-3001 https://doi.org/10.1002/anie.201105984

86 Daube, D., Aladin, V., Heiliger, J., Wittmann, J.J., Barthelmes, D., Bengs, C. et al. (2016) Heteronuclear cross-relaxation under solid-state dynamic nuclear polarization. J. Am. Chem. Soc. 138, 16572-5 https://doi.org/10.1021/jacs.6b08683 